\title{
The Role of Cultural Capital in Organizational Citizenship Behavior (Case Study: Islamic Azad University of Mahmudabad)
}

\author{
Faranak Paydar ${ }^{1} \&$ Mohammad Salehi ${ }^{2}$ \\ ${ }^{1}$ Department of Educational Management, Mahmudabad branch (Noor), Islamic Azad University, Mahmudabad, \\ Iran \\ ${ }^{2}$ Department of Educational Management, Sari Branch, Islamic Azad University, Sari, Iran \\ Correspondence: Faranak Paydar, Department of Educational Management, Mahmudabad branch (Noor), \\ Islamic Azad University, Mahmudabad, Iran. E-mail: paydarfaranak@yahoo.com
}

Received: December 18, 2016

Accepted: December 21, 2016

Online Published: April 18, 2017

doi:10.5539/res.v9n2p130

URL: http://doi.org/10.5539/res.v9n2p130

\begin{abstract}
Background: Developing and strengthening Organizational and Citizenship Behavior (OCB) needs various capitals such as Cultural Capital. The aim of this research was studying about the relation between cultural capital and organizational citizenship behavior and also predicting organizational and citizenship behavior.

Materials and Methods: The method of this study was description. The Statistical population under study was composed of 380 MA students in Mahmud-Abad Islamic Azad University. Finally on the basis of Kook ran formula a sample of 191 people was chosen randomly stratified for this study. Standard questionnaire was used in this study. Bourdieu standard cultural capital questionnaire with kronbakh alpha factor .857 and Organ and Kanoski organizational and citizenship behavior questionnaire with the stability of .76 were used in this study for statistical analysis data with Pierson and Regression correlation factor was used to check the hypothesis. All data analysis was done with Spss 18.
\end{abstract}

Results: Achievements of this study were shown that there is a meaningful correlation between cultural capital and $\mathrm{OBC}$ with the factor of 0.428 . Also cultural capital with determination factor of .183 plays an important role in predicting $\mathrm{OBC}$.

Conclusion: Therefore universities must improve their culture index regarding their cultural mission in order to improve OBC which is a valuable and useful behavior. They achieve sustainable development through their evolutionary process.

Keywords: cultural capital, organizational citizenship behavior, Islamic Azad university of Mahmud-Abad

\section{Introduction}

Bourdieu invented the concept of cultural capital in order to resolve this issue: "economic barriers are not sufficient to explain existing inequalities in students' educational success at different social classes. Bourdieu's most important theory is the theory of action, which in this theory tries to determine principles governing human behavior, which based on the concept of manner and its interaction with that". In Bourdieu's approach, the action function is the actors' features in interaction with the force of a special field. Also, manners are the systems of stable and portable capabilities that change the external structure into internal, such that individuals reproduce structures with their actions (Babaifard \& Heydarian, 1394). According to Bourdieu, all human beings are actors, whether who knowingly does the action or those unconsciously embrace the domination; in other words, active and passive people are actors, and action is an act that occurs in a field and each field is an area in which actual and potential forces will have exchange with each other's. Such as: society and organization. Therefore, to understand the meaning of action, we have to realize the meaning of the field which is the result of the exchange between forces. Mental structure of each person and the situation called field that have occupied in society depend on the utilization of capital. This is the capital that allows person to control their own and others destiny (Abbaszadeh, Mirzaee, \& Aliyari, 1394). In Bourdieus' believes the capital can have various forms of economic, social and cultural (Hariri Akbari \& Salehinejad, 1394). Economic capital: wealth and money which are in hands of any social actor will be used in production of goods and services as an ownership and financial and institutional assets (Babaifard \& Heydarian, 1394). Social capital: Hanifen, have known the social capital as 
set of assets such as altruism, sympathy, fellowship and the friendship among individuals and families that people use them in their daily life (Fatehi \& Ekhlasi, 1392). Bourdieu describes social capital as a form of capital which is associated with other types of capital but separated from them. Social capital is the position, relationships in groups and social networks that increase the accessibility of opportunities, information, financial resources and social status of people. This capital is an actual and potential resources that are the result of a durable network possession from institutional relationships among people and it other words a membership in a group (Khajehnoori, Parnian, \& Hemat, 1393). Cultural capital: in the past, cultural capital was a personal capital and considered as an individual dimension, so it can be named as a set of relationships, knowledge, information and rates, that person used it to maintain or obtain the social status. But todays and in current global network, cultural capital is considered as an effective factor in national development, both in individual and social dimension; so, promotion and development in cultural capital are considered as cultural sustainable development in communities (Sepehrnia, 1394). All capital links together and convertible to each other but its exchange rate is different: 1) Economic capital will exchange to others more quickly in comparison to cultural and social one. 2) Erosion and destruction speed of social capital is far greater than the economic cultural one. 3) Cultural capital is the most stable and constant capital (Darini et al., 1394). In prominent community, it's not impossible but is so hard to develop very quickly in all socio-economic areas. Currently, more than any other time, due to the economic-financial downturn, some items should be considered, include: deeper understanding of OCB; find out the real reasons that members of organization act in order to increase individual and group performance and also study the ways in which their behavior effects on organizational performance. For this reason, it is essential to study and understand the behavior of member of the organization over the limits imposed by Regulations. Understanding this complex behavioral mechanisms and proper evaluation of their impact on organizational performance at management level may create new opportunities to improve performance at both individual and organizational level (as a whole), which may have a decisive share in achieving organizational goals (Popescu \& Diakonov, 2015). The concept of OCB is presented to the world of science in early 1980s, first by Batman and Organ. Katz and Kahn in seventies and earlier by distinguishing between role of performance and "innovative and spontaneous" behavior and Chester Barnard (1938) by describing the meaning of "willingness to cooperate" were considered the personality features (Bin Stook et al., 2003). OCB has been studied since 1970. Researchers have developed variety of actions for OCB. Empirical research is focused on the consequences of OCB which focused on organizational performance. OCB includes behavior to do things and needs (Willdrum, 2014), that have important role in organization success in both individual and organizational levels (Depin, Pustifeul, \& Soju, 2015). In this study seeks to examine the role of cultural capital to determine the OCB. That can be able to make changes in OCB through realizing this role, making culture and cultural capital level promotion and follow the patterns, symbols based on culture of each country and also, by the OCB promotion is able to move effectively towards the promotion of countries cultural capital level. Considering the importance of the issue, this is the question that how much does the cultural capital have an effect on determining OCB? Assumption was considered in this study which includes one main and six secondary hypotheses. Research main hypothesis: there is a meaningful relationship between cultural capital and OCB. The secondary hypothesis of research respectively, include: 1) there is a meaningful relationship between cultural capital and altruism. 2) There is a meaningful relationship between cultural capital and conscience. 3) There is a meaningful relationship between cultural capital and generosity. 4) There is a meaningful relationship between cultural capital and civil behavior. 5) There is a meaningful relationship between cultural capital and politeness and consideration. 6) Cultural capital predicts OCB of students. Finally, considering the intended assumption and conducted theoretical studies. The conceptual model were extracted in Figure 1 and be tested. 


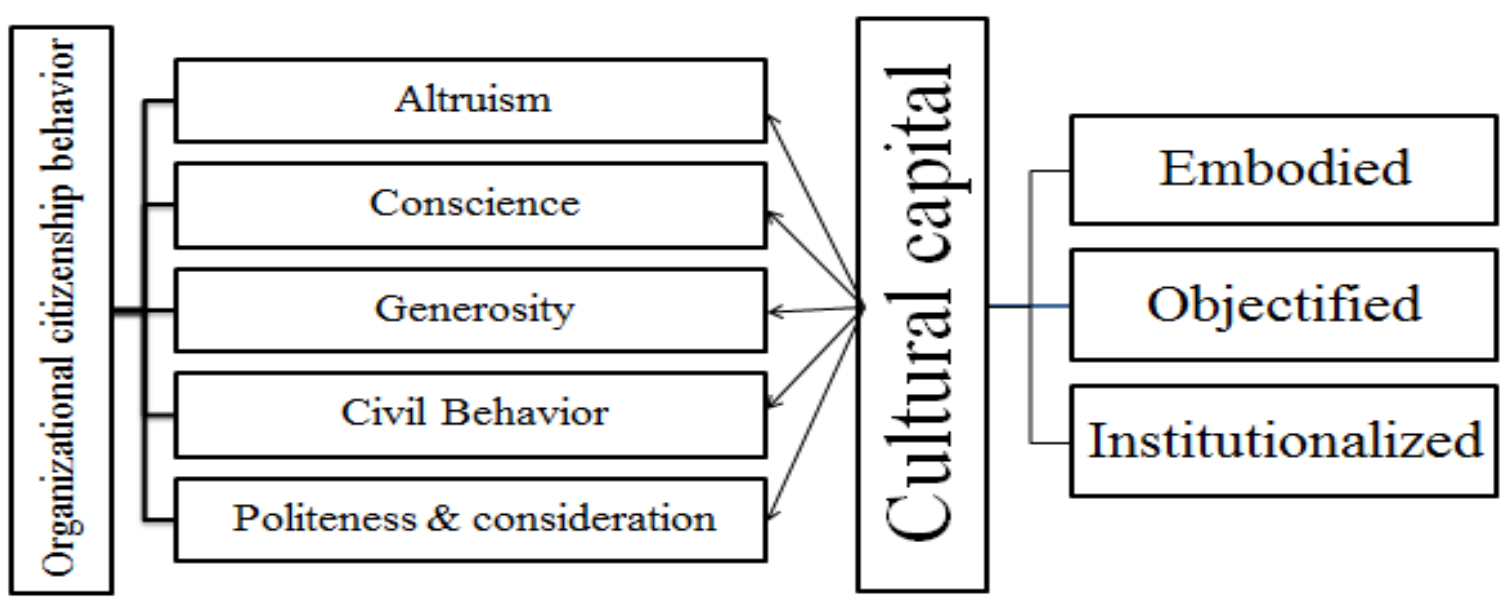

Figure 1. Research conceptual model

\section{Theoretical Foundations}

Capital: according to Bourdieus' view, capital refers to any resources which affects certain areas, and allows people to achieve special benefits through participation in the competition for that (Qasemi \& Namdar, 1393).

Capital types: Flora (2003), said capital types include political, human, social, constructional, natural and cultural capital (Roohani, 1388), and Figure 2 shown the relationship among all kinds of capital.

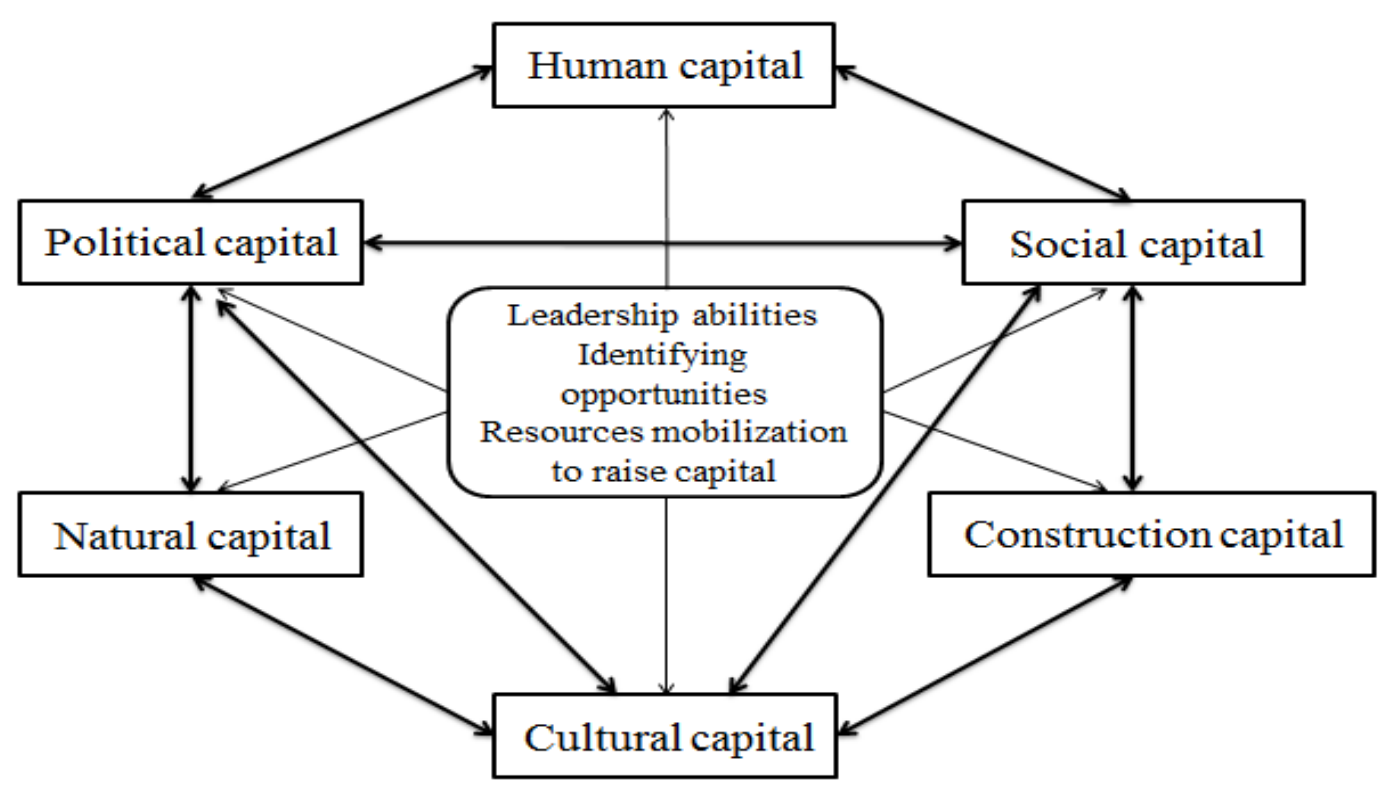

Figure 2. The relation among capital types

Cultural capital: according to Bourdieu, cultural capital refers to different groups life style features, tasted, cultural merits and cooperation, and also tends to political culture and morality (Sharbatian \& Eskandari, 1394). Bourdieu says that, cultural capital has been described as familiarity with the guidelines and cultural codes inscribed in the community. He argues that cultural resources constitute a kind of immaterial capital which in equal terms should be considered as an economic resource (as economic capital) and social networks (as social capital). Cultural capital has been included Individuals and families and it was transmitted from parents to children through investing and socializing. Actually, cultural capital can be converted to social and economic capital (Gran Andersen Jagger, 2015). Based on Bourdieus' view, cultural capital is divided into three categories: 
embodied cultural capital, objectified cultural capital and institutionalized cultural capital (Wilkinson \& Levins, 2014): 1) Embodied cultural capital: including both conscious acquisition and passively inheritance of a person. Cultural capital is not transmitted spontaneously, but it's the result which embodied him as a person during his time. 2) Objectified cultural capital: cultural capital that had been owned as physical objects. 3) Institutionalized cultural capital: kinds of cultural capital that often known as persons reputation or scientific qualities (Sadeghi et al., 1394). Organizational Citizenship Behavior (OCB): according to Organ (1988), OCB represents the behavior of a person who directly or explicitly did not recognized by the formal reward system. And in general leads to effective performance of organization (Akrai \& Aktoran, 2015). Organ (1977) stated that the five dimensions of OCB can be classified as: 1) Altruism: reflects the individuals' voluntary willingness to help doing specific tasks or workplace problems. 2) Politeness and consideration: put yourself in sight, respect and consideration of others. 3) Generosity: is the expression of love or tolerance, avoidance of complaints and dissatisfaction attitude, endure the inevitable discomfort and displeasure at workplace. 4) Conscience, means employees optimistic attitude towards work, in which person, is sensitive and sensible into the rules and procedures of the company. 5) Civil behavior: is defined as a responsible participation in organizational activities. As an example, participation in charity events which financially supported by organization (Zayas et al., 2015).

\section{Literature}

According to studies were made within the country and abroad, we have extracted similar researches that conducted in fields of cultural capital and OCB, that express them here. For example some similar researches have been done abroad, including: Sariq, Ye-Yang and Sukumar (2016), in an article entitled "job attitudes management: job satisfaction role and organizational commitment on OCB", they collected data through questionnaires among 250 secondary school teachers in Prague, to assess the relationship between job attitudes and OCB among secondary school teachers. The results show that there is a positive and meaningful relationship between job satisfaction, organization commitment and OCB. Davis, Palashz, Maria and Alguasil (2016), in an article entitled "organizational commitment and its effects on OCB in an environment with high unemployment", assessed the relationship between triple dimensions of organizational commitment (emotional, normative and ongoing commitment) and employees' OCB in high unemployment environment. The results of this study show that, in a high unemployment environment, dimensions of the emotional, normative commitment have similar behavior towards a full employment environment. Continuous commitment dimension, have a significant increase in an environment with high unemployment. Ezmir and Argon (2015), in an article entitled "the relationship between organizational socialization and OCB: the mediating role of person-environment fit", which aims to study the effects of person-environment fit in relation to organizational socialization and OCB have been done on 202 white-collar employee in Istanbul, they conducted that, there is a relation between all dimensions of socialization (job knowledge, organizational values and goals, performance skill, language, and people) and OCB (altruism, humanity, civic virtue, and athleticism). Therefore; person-environment fit (person-organization fit, person-supervisor fit and ability-wish fit), is the mediator between socialization and OCB. Dumais (2015), in an article entitled "education and cultural capital", presented the definitions of cultural capital and its theoretical concept, with special focuses on relationship between cultural capital, education and learning results. In this study, a review of Bourdieu's' theory of social and economic reproduction, focusing on the role of cultural capital is expressed. Molgard and Jagger (2015), in an article entitled, "the effect of grandparents social, cultural and economic capital in grandchildrens' educational success", analyze the effects of grandparents social, cultural and economic capital in grandchildren's educational success. According to data were collected in Denmark and Scandinavia, it was assumed that grandparents economic capital in Denmark in compared to Scandinavia should have less important, while social and cultural capital should be relatively more important. This assumption was confirmed by the result to some extent parents cultural capital (not social and economic capital) has a positive effect on student to choose science trace in high school rather than other one. Results shows that, at least in Scandinavia, the grandparents' ways which effect on grandchildren's educational success is though non-economical resource. Now we express some similar research have conducted in the country Shahramnia, Marandi et al. (1394) in an article entitled "the relation of cultural capital and media consumption", have conducted that, there is a meaningful relation between media consumption (printed, electronic and digital) and cultural capital (subjective, objective and institutional). There is a meaningful relation between all media dimension and subjective and objective dimension and cultural capital, but there is a negative relationship between cultural capital and printed media. Mirfard, Ahmadi et al. (1394), in an article entitled "cultural capital of agricultural and industrial cooperative in Boyerahmad, investigate the cultural capital in agricultural and industrial cooperative in Boreahmad". Results of this research confirms linear correlation, the effect of behavior variables, cultural procedures and total elements of cultural capital on agricultural and industrial cooperatives. Also, both behavior and cultural procedures and cultural goods consumption of cooperative members be able to 
clarify $33.6 \%$ of cooperative performance variance. There no meaningful difference between cooperative performance due to the sex, marital status, educational level, activity records and cooperative membership history. Salehi-Amiri, rezaei (1393), in an article of "investigate the effect on cultural capital on students' scientist productions", considered three elements of cultural capital which include: objective, identical and institutional, that based on this article, the relationship between cultural capital component and scientific productions we approved. Qasemi and Namdar (1393), in an article entitled "investigate the relation of cultural capital and symbolic cultural capital (case study: students of Ilam university)", considered three embodied, objectified, and institutionalized capital as cultural capital components. Intensity of cultural capital (embodied, objectified and institutionalized) are meaningful and with cultural capital equals $0.833,0.186,0.714$ respectively and rates of full cultural capital relationship with symbolic cultural capital is meaningful and equals 0.754 .

Results indicate that hierarchy existence of cultural capital, leads to symbolic cultural conflict, and if reference (for cultural imitation) be the people themselves, and have less gap with different levels, will be better accepted; so symbolic cultural authority can be used to policies and social grouping in society.

\section{Methodology}

In this paper, the research model is a conceptual model. Given that today Bourdieu's view are presented more than other theoretical approaches in relation with cultural capital and were developed, so, in this paper, parts of the model that related to cultural capital have been used Bourdieu's three indexes with six components Bourdieu's six indexes include: embodied, objective and institutionalized cultural capital (Qasemi \& Namdar, 1393). Embodied cultural capital index have components of subjective kills and expertise in course material expression. Objective cultural capital index includes component of cultural goods usage, cultural goods ownership and art interest. And finally, institutionalized cultural capital index has education certification index. The other part which related to OCB includes five indexes of OCB. Organ summarizes OCB's indexes in five dimension which mostly used in research. These five dimensions include: job conscience, generosity, civil virtue, altruism, respect and honor. He named both altruism and respect and politeness dimension of individual dimensions of OCB, because their attitude refers to the person, and the other dimensions (generosity, civil virtue and loyalty) called organizational factors of OCB. Current research is descriptive in terms of applied goal, procedures and data collection. Due to investigate relationship among variables of Pearson correlation and regression, statistical population include 330 MA students of Islamic Azad university in seven majors and to determine the sample size kokran formula is used, which on this basis, 191 subjects were selected randomly as sample and Spss 18 is used in order to data analysis. Here we have used both Bourdieu standard questionnaire with 85.7 reliability and Organ and Kanoski questionnaire with 0.76 reliability as research tools.

\section{Data Analysis}

\subsection{Demographic Findings}

Demographic findings shown that $63 \%$ subjects are female students and $37 \%$ are males. Descriptive findings in Table 1 shown that the average of subjects responses to the OCB and cultural capital questionnaire are higher than average (3) that represents the desirable level of these two variable among subjects of descriptive terms.

Table 1. Description of variables

\begin{tabular}{ccccc}
\hline Standard deviation & Average replies & Maximum & Minimum & Variable \\
\hline 0.91 & 3.30 & 5 & 1 & Cultural capital \\
0.65 & 3.43 & 4.74 & 1.11 & OCB \\
\hline
\end{tabular}

\subsection{Inferential Findings}

Inferential findings shown that there is a meaningful relation between cultural capital and OCB dimensions. As regards to the amount of p-value in Table 2, is lower than 0.05 errors and also if Pearson coefficient be positive, indicates that there is a direct relationship among variables. 
Table 2. Description of variables

\begin{tabular}{cccc}
\hline p-value & Errors & Pearson coefficient & Variable \\
\hline 0.000 & 0.05 & 0.428 & Cultural capital and OCB \\
0.000 & 0.05 & 0.379 & Cultural capital of altruism \\
0.000 & 0.05 & 0.443 & Cultural capital with conscience \\
0.003 & 0.05 & 0.215 & Cultural capital with Generosity \\
0.002 & 0.05 & 0.218 & $\begin{array}{c}\text { Cultural capital of civil behavior } \\
\text { Cultural capital politeness and } \\
\text { considerate }\end{array}$ \\
\hline 0.000 & 0.5 & 0.352 &
\end{tabular}

As shown in Table 3, can be seen, correlation among variables equals to 0.428 that indicates the average correlation among variables. Also, due to the coefficient of determination, this results is achieved that cultural capital variables were accounted only 0.183 of changed of $\mathrm{OCB}$, and the rest is related to other factors that not examined in this paper.

Table 3. Short regression model

\begin{tabular}{cc}
\hline $\mathbf{R}^{2}$ (coefficient of determination) & $\mathbf{R}$ (the correlation between variables) \\
\hline 0.183 & 0.428 \\
\hline
\end{tabular}

Given that in Table 4, Sig amount (meaningful level) is meaningful, this result obtained that the regression equation is meaningful, and indeed we are allowed to use the regression equations.

Table 4. Table ANOVA

\begin{tabular}{ccc}
\hline Sig (Significance level) & Degrees of freedom & F \\
\hline 0.000 & 1.189 & 42.35 \\
\hline
\end{tabular}

As shown in Table 5, the amount of Sig is lower than 0.05 error level, so cultural capital variables remains in regression model and indeed it have sake in OCB"s prediction.

Table 5. Regression coefficients

\begin{tabular}{cccccc}
\hline \multirow{2}{*}{ Model } & \multicolumn{2}{c}{ Non-standardized coefficients } & Standardized coefficients & \multirow{2}{*}{ T } & Sig \\
\cline { 2 - 3 } & $\mathrm{B}$ & standard error & Beta & & \\
\hline Constant value & 2.043 & 0.160 & & 12.73 & 0.000 \\
Cultural capital & 0.305 & 0.047 & 0.428 & 6.50 & 0.000 \\
\hline
\end{tabular}

\section{Discussion and Conclusion}

Findings show that the higher the cultural capital, their OCB will develop more. Cultural capital mostly means higher cognitive and have tendency to higher noble behavior, which will have great impact in promoting citizenship behavior. Because in any organization, human capital is the most important factor, so we have pay attention to changes in attitudes and staff habits to create change and improvement in organization. Because of Bourdieu's belief, cultural habits potentially have a talent to use by groups and individuals, and have resources that cab bring many benefits (Wilining, 2003). Strengthening citizenship behavior like any others that we do, 
needs to be encouraged cultural capital and encourage habits and valuable attitude can be effective in this areas. Also, it would increase the effectiveness and efficiency of the organization. Achieve an acceptable level of cultural capital requires times to train and develop human capital. As universities always are responsible for the mission of restoration and cultural development, so this is the university should start and by providing suitable educational designs and convergent environment towards organizational and human goals leads to emergence of valuable behavior of extra-role of organizational citizen.

\section{Practical Suggestions}

Cultural capital makes people to have better recognize their social environment and adhere to it. So, it's suggested that educational institutions, including universities, emphasize on creating cultural capital as the most important factor of scoring and empowering as such it provides intellectual growth, social mobility, loyalty, voluntary and altruistic behavior that essential for life of human society. Since the cultural capital is essential and people in organization will be offer in order to organizational promotion, and organization goals more quickly will be achieved. It is suggest that this research be done on non-educational organizations, to feel more the need to investment in cultural sector, and also they use advanced software in order to modeling and presenting suitable model to develop the organizations.

\section{References}

Abbas-Zadeh, M., Mirzaee, H., \& Aliary, L. (1394). Social and cultural capital effect on participation of citizens in the separation and collection of household waste (sample of study is Urmia citizens). Urban Sociological Studies, 5(14), 75-102.

Acaray, A. A. (2015). The Relationship between Organizational Citizenship Behaviour and Organizational $\begin{array}{llll}\text { Silence. Procedia-Social and Behavioral Sciences, 207(2015), } & \text { 472-482. }\end{array}$ https://doi.org/10.1016/j.sbspro.2015.10.117

Babaei-fard, A., \& Heydarian, A. (1394). Investigation the cultural capital effect on educational achievement. Semiannual Journals Social Science, 12(1), 117-142.

Bienstock, C. C., Demoranville, W. C., \& Smith, K. R. (2003). Organizational Citizenship behavior and service quality. Journal of Services Marketing, 17(4), 357-378. https://doi.org/10.1108/08876040310482775

Darini, V. M., Taban, M., Namdar, E., \& Bahonar, N. (1394). Investigation the relationship between symbolic capital and cultural capital (case study: Students of the Ilam University). Journal of Culture-Communication Studies, 16(31), 177-197.

Deepaen, W. P., \& Shotig, S. S. (2015). Development and Preliminary Psychometric Properties of Teachers' Organizational Citizenship Behavior Scale. Procedia-Social and Behavioral Sciences, 191(2015), 723-728. https://doi.org/10.1016/j.sbspro.2015.04.710

Devece, C. P. M., \& Daniel, P. A. M. (2016). Organizational commitment and its effects on organizational citizenship behavior in a high-unemployment environment. Journal of Business Research, 69(5), 1857-1861. https://doi.org/10.1016/j.jbusres.2015.10.069

Dumais, S. A. (2015). Cultural Capital and Education. In International Encyclopedia of the Social \& Behavioral Sciences (2nd ed., pp. 375-381). https://doi.org/10.1016/B978-0-08-097086-8.10433-7

Fatehi, A., \& Ekhlasi, E. (1392). Factors Affecting on Social Capital (Case Study: Pre-university students of Shiraz). Journal of Social Welfare and Development Planning, 14, 145-181.

Ghasemi, Y. M., \& Namdar, E. (1393). Investigation the relationship between cultural capital and symbolic cultural capital (Case Study: Ilam University students). Journal of Elamite Culture, 15(44), 7-21.

Gholipour, A., Pour-ezzat, A. A., \& Sa'idinejad, M. (1386). Factors causing anti-citizenship behaviors in organizations. Journal of Management Sciences in Iran, 2(8), 1-29.

Gran, A., \& Ida-Meier, J. M. (2015). Cultural capital in context: Heterogeneous returns to cultural capital across schooling environments. Social Science Research, 50(2015), 177-188. https://doi.org/10.1016/j.ssresearch.2014.11.015

Hariri akbari, M., \& Saleh-nejad, H. (1394). Cultural capital is a barrier to social alienation (case study: Students of Saqez). Journal of Sociological Studies of Youth, 17, 33-56.

Khaje-noori, B., Parnian, L., \& Haniat, S. (1393). The study of the relation between social, cultural capital and social identity (Case Study: Bandar Abbas Youth). Journal of National Studies, 15(1), 95-120. 
Mirfrdi, A., Ahmad, S., Sadeq-nia, A., \& Rostami, M. J. (1394). The role of cultural capital in Boyer-ahmad agricultural and industrial cooperatives performance. Journal of Agricultural Cooperatives, 4(14), 127-143.

Mohamed, T., Shafazawana, Y. Y., Cheah, M. S., \& Zuliawati, S. K. (2016). Managing Job Attitudes: The Roles of Job Satisfaction and Organizational Commitment on Organizational Citizenship Behaviors. Procedia Economics and Finance, 35(2016), 604-611. https://doi.org/10.1016/S2212-5671(16)00074-5

Mollegaard, S., \& Jæger, M. M. (2015). The effect of grandparents' economic, cultural, and social capitalon grandchildren's educational success. Research in Social Stratification and Mobility, 42(2015), 11-19. https://doi.org/10.1016/j.rssm.2015.06.004

Organ, D. W. (1988). Organizational citizenship behavior: The good soldier syndrome. Lexington, MA: Lexington Books.

Özdemir, Y. E. S. (2015). The relationship between organizational socialization and organizational citizenship behavior: The mediating role of person environment fit. Procedia-Social and Behavioral Sciences, 207(2015), 432-443. https://doi.org/10.1016/j.sbspro.2015.10.113

Popescu, A. M. D., \& Alecxandrina, P. T. (2015). Organization's age and Organizational Citizenship Behavior (OCB), performance criteria at SMEs level: Case study-Bucharest-Ilfov development region. Procedia Economics and Finance, 22(2015), 645-654. https://doi.org/10.1016/S2212-5671(15)00278-6

Roohani, H. (1388). Introduction to the theory of cultural capital. Journal of Strategy, 18(53), 7-35.

Sadeqi, S. K., Ranj-poor, R., Motefaker-Azad, M. A., Asadzadeh, A., \& Garshasbi-Fakhr, S. (1394). The estimated cultural capital process in Iran. Journal of the Socio-Cultural Strategy, 4(15), 155-192.

Salehi-Amiri, S. A., Rezaei, A. A., \& Aznav-zad, G. (1393). Investigation the cultural capital effect on students' scientific production. Journal of Socio-Cultural Development Studies, 3(1), 93-113.

Sepehrnia, R. (1394). Creative attitude to the tourism industry in promoting cultural capital in Iran. Journal of Scientific-research Initiative and Creativity in the Humanities, 4(4), 51-70.

Shahram-nia, A. N., Marandi, Z., Mehrabi, K. R., \& Sistani, M. (1394). The relation between media consumption and cultural capital. Cultural Social Journal of Social Welfare, 15(59), 189-221.

Sharbatian, M. H., \& Eskandari, Z. (1394). Sociological analysis of indexes of cultural capital and its effective factors (Case study: Female students of Payam Noor and Islamic Azad University Qaen). Journal of Khorasan Cultural Social Studies, 38, 57-84.

Weininger, E. L. A. (2003). Translating Bourdieu into the American context: The question of social class and family-school relations. Poetics, 31(5-6), 375-402. https://doi.org/10.1016/S0304-422X(03)00034-2

Willekens, M. L. J. (2014). Family (and) culture: The effect of cultural capital within the family on the cultural participation of adolescents. Poetics, 42, 98-113. https://doi.org/10.1016/j.poetic.2013.11.003

Yildrim, O. (2014). The Impact of Organizational Communication on Organizational Citizenship Behavior. Procedia-Social and Behavioral Sciences, 150(2014), 1095-1100. https://doi.org/10.1016/j.sbspro.2014.09.124

Zarei-Matin, H., Alvani, S. M., Jandaghi, G. R., \& Ahmadi, F. (1389). Presentation a comprehensive model effective factors on OCB development (employees of Iran National Oil Company).

Zayas-Ortiz, M. R., Ernesto, M., \& Eulalia, C. G. P. (2015). Relationship between organizational commitments and organizational citizenship behaviour in a sample of private banking employees. International Journal of Sociology and Social Policy, 35(1/2), 91-106. https://doi.org/10.1108/IJSSP-02-2014-0010

\section{Copyrights}

Copyright for this article is retained by the author(s), with first publication rights granted to the journal.

This is an open-access article distributed under the terms and conditions of the Creative Commons Attribution license (http://creativecommons.org/licenses/by/4.0/). 